\title{
Correspondence
}

\section{Birthweight between 14 and 42 weeks' gestation}

Sir,

We were interested to read the recent paper by Keene and Pearse. ${ }^{1}$ Unfortunately the emphasis placed on ultrasound assessment in respect of other methods of assessing gestational age was not disclosed. We believe it is important to stress the limitations of ultrasound.

Most departments of obstetrics use ultrasound routinely to assess gestational age. A fetal measurement (usually biparietal diameter) obtained by ultrasound is plotted on a chart to obtain gestational age. An assumption is made, however, that the fetus is on the 50th centile for that parameter. By definition most fetuses will not be on the 50 th centile and hence this assumption may lead to considerable error. Serial ultrasound measurement to assess fetal growth velocity is a more appropriate use of ultrasound. This error in the method may account for some of the differences observed by Keene and Pearse from previous studies. ${ }^{2}$

R Stanhope AND C G D Brook The Middlesex Hospital, London WIN $8 A A$

Drs Keene and Pearse comment:

While agreeing with Drs Stanhope and Brook on the limitations of fetal ultrasonography, we are unable to accept their suggestion that the differences between our data $^{1}$ and those of Gairdner and Pearson ${ }^{2}$ are due to our reliance on this method of assessing gestational age.

Firstly, as our paper made clear, both ultrasonography and the Dubovitz method of gestational assessment were innovations used in this area and both were used alongside traditional methods calculated on the last menstrual period. Where there were gross discrepancies, paediatric assessment became the most important parameter, the baby himself being the most tangible of the three.

While it is indisputable that most fetuses will not be on the 50 th centile, we would point out that equal numbers lie above and below that centile. Hence, it might be supposed that any errors in gestational assessment by ultrasound would also be equally distributed above and below that point, and so would not affect the mean. In our view, however, it is not the distribution of ultrasound data around the mean which is problematic, but the derivation of the mean itself. The problem with all methods of gestational assessment is that they are standardised on the last menstrual period, and given the variable relation between this and ovulation it is probably illusory to regard gestational assessment by any method as accurate to more than \pm 1 week at the most optimistic.
Secondly, our paper referred to the problem of comparability between fetal growth charts as a consequence of the differential exclusion of data. We would suggest that this is much more likely to account for the difference observed between our data and those of Gairdner and Pearson. ${ }^{2}$ The Gairdner and Pearson chart is based on data given by Thomson, Billewicz, and Hytten. ${ }^{3}$ The babies in this study are, in fact, among the largest reported in the world, and as Thomson and Tanner ${ }^{4}$ note, are certainly larger than those of the British Perinatal Mortality Study of $1958 .^{5}$ It is interesting to note that the Thomson, Billewicz, and Hytten sample excluded illegitimate births (ranging from 5 to $6 \%$ of all births in Aberdeen during the study period) and a further $10 \%$ of data where it was not possible to date the last menstrual period accurately. Overall, in other words, some $14 \%$ of births were excluded.

If these exclusions had been random, the results of the study would not have been biased. There are, however, grounds for believing that they were not random. The mean weight of the excluded $10 \%$ was $0.08 \mathrm{~kg}$ lower than the rest of the sample and the authors believed there was an excess of mothers of low social class. Given the association of illegitimacy, low social class, and low birthweight, there is reason to suppose the Thomson, Billewicz, and Hytten study (and consequently the Gairdner and Pearson chart) to be biased towards higher birthweight.

\section{References}

' Keene DV, Pearse RG. Birthweight between 14 and 42 weeks' gestation. Arch Dis Child 1985;60:440-6.

2 Gairdner D, Pearson J. A growth chart for premature and other infants. Arch Dis Child 1971;46:783-7.

3 Thomson AM, Billewicz WZ, Hytten FE. The assessment of fetal growth. Journal of Obstetrics and Gynaecology of the British Commonwealth 1968;75:903-16.

${ }^{4}$ Tanner JM. Thomson AM. Standards for birthweight at gestation periods from 32 to 42 weeks allowing for maternal height and weight. Arch Dis Child 1970;45:566-9.

5 Butler N, Alberman E. Perinatal problems. 2nd report of the 1958 British Perinatal Mortality Study. London: Livingstone, 1969.

\section{Oxandrolone in low dose for constitutional delay of growth and puberty in boys}

Sir,

I read the paper by Drs Stanhope and Brook ${ }^{1}$ with interest and strongly support them in their last paragraph where a plea is made for the ready availability of oxandrolone. I have, however, a number of anxieties about the data presented in their paper and am not convinced that they have shown all that they claim. 